\title{
Contrastive Analysis about the Case of Public Bicycle System Among Three Cities in Shandong
}

\author{
Song Chuanzeng ${ }^{1, a}{ }^{*}$, Fa Zheng ${ }^{2, b}$, Li Xinlei ${ }^{3, c}$, Song Haiyang ${ }^{4, d}$ \\ ${ }^{1,2,3}$ Traffic Engineering College, Shandong Jianzhu University, Jinan, Shandong, China \\ ${ }^{4}$ Architecture and Urban planning College, Shandong Jianzhu University, Jinan, Shandong, China \\ asong1@sdjzu.edu.cn, bamfazheng@163.com, 'Sdjzlx|@126.com, dsong80696970@126.com
}

Keywords: Municipal facilities, Public bicycle system, Green transportation, Case analysis, Countermeasures

\begin{abstract}
Recently, traffic problem like viruses spread to small and medium-sized cities in China. The bicycle transportation plays a unique role in the process of alleviating traffic congestion and promoting the development of green transportation. Bicycle transportation is a main part of urban slow traffic system and it has outstanding advantages in mid-and-short travels for solving the traffic problem by connecting bus stops and starting points. And it is also a kind of transportation tool that can keep one's physical health. The urban bicycle transportation has become a mainstream concept for fashion, green, environment friendly, sports and health in China. Obviously the development of urban public bicycle system has to be in line with this fashion. The purpose of developing public bicycle system is to reduce the flow of motor vehicles, to alleviate traffic pressure, to lower traffic pollution and energy consumption so as to make it convenient for citizens' travel, which is related to the lives of people and urban sustainable development. This paper, on the basis of summarizing public bicycle system at home and abroad, stresses on the analysis of three typical cases for public bicycle system in Qingzhou, Yantai, and Zaozhuang of Shandong, and discusses the operating modes, service features, implementation effects and existing problems in these three public bicycle systems to provide candidate solutions to deploy the public bicycle systems in the medium and small cities.
\end{abstract}

\section{Introduction}

China has a reputation of "bicycle kingdom". The bicycle transportation is an important part of China's urban slow traffic system. The amount of production and sales in China accounted for more than $90 \%$ of the world's, and exports has been occupy $61.7 \%$ of global exports. The Building Department, the National Development and Reform Commission and the Ministry of Finance released guidance on strengthening the construction of urban pedestrian and bicycle transportation system (construction [2012] No. 133) on September 5, 2012 [1] .It pointed out that in order to solve the short and medium distance travel and transfer to public transportation, it is necessary to develop bicycle transportation in metropolis; and it also should be focally developed as a main traffic way in small and medium-sized cities. According to urban population, has been given the ration of traveling by foot and by bike till 2015.It should reach amount $45 \%$ for a city of 10 million citizens; $50 \%$ for a city of 5 million citizens; $55 \%$ for a city of 2 million citizens; $65 \%$ for a city of 1 million citizens; over $70 \%$ for all other cities. Promoting public bicycle system can save energy, reduce carbon emissions and fine particulate (PM2.5). It has significance to improve the urban traffic structure and alleviate traffic congestion as well. While, the public bicycle system also encountered some inevitable problems, such as unreasonable design and construction, existing security risk [2] and lacking perfect logistics [3], etc. At present, most related studies [4] on the construction and optimization of the public bicycle system focus on big cities, few literatures do deep analysis on medium and small cities' development pattern. With the support of Natural Science Fund of Shandong and Scientific Research Projects of Building Department, the research team made a survey about three typical public bicycle systems in Qingzhou, Yantai and Zaozhuang, analyzed and summarized the experience and lessons during providing service to these three public bicycle 
systems, and offered enlightenments and scientific basis for the development of public bicycle system in other cities.

\section{Features of Bicycle Transportation}

The features of Bicycle transportation are described as below: (1). The bicycle energy equal to one's physical fitness. It is unlike a car consuming fossil energy, with no pollution, little noise, green environment friendly. (2).Comparing with public transportation, it is convenient, flexible, autonomous, accessible, and punctual. (3).It is easy to maintain and has low price and traveling time. (4).It calls for low demand of road conditions, because its small size and flexibility make it possible to ride in narrow lanes. (5). Travel distance and speed mainly depends on one's physical condition; it's an ideal short distance traveling mode and a transfer mode. (6). The per capital occupancy road area is less than other traveling mode, referring to detailed data in table 1 . And it only need 1 to 2 square meters space to park one bicycle. (7).It is poor stability, poor safety, and easy to cause traffic accidents if driving both on the motor and non-motor vehicle lanes. Therefore we should promote the advantages but avoid its shortcomings.

Table 1 per capital occupancy road area of every traffic way

\begin{tabular}{ccccc}
\hline Every indicators & Bicycle & Car & Bus & Subway \\
\hline Average driving speed[m/s] & 12 & 45 & 25 & 40 \\
\hline occupancy parking area[person] & 1.5 & $4 \sim 6$ & $1.5 \sim 2$ & 0 \\
\hline occupancy road area[person] & $6 \sim 10$ & $10 \sim 20$ & $1 \sim 2$ & 0 \\
\hline Table 2 the equivalent value of death toll in accident for every transportation per unit \\
\hline Pedestrian & Bicycle & Motor bicycle & Motor vehicle \\
\hline 3.55 & 2.34 & 1.17 & 1.00 \\
\hline
\end{tabular}

\section{Brief Introduction of Public Bicycle at Home and Abroad}

"Public Bicycle" ,originally from the "white bicycle plan" of Amsterdam in the Netherlands in 1965, has developed into the third generation of public bicycle systems that are combined with computer technology, communication technology, information integration and the Internet technology [5]. It is applied in many cities. Motor vehicle flow has dropped by $4 \%$ after promoting public bicycle project in Lyon. In 2007, Paris governmentlaunched1450 stops for the public bicycle project. A net rental site is placed for every 200 meters where has twenty thousand public bicycles. It is for free within the first half hour at a time. London invested ten thousand public bicycles in 2010, and built 400 stops and a 273-mile bicycle lane. After sending a message to service center with a mobile, citizens will receive an unlock password to take and parking a bicycle at any stops. Copenhagen built 150 stops. A bicycle can be taken by putting a 20-koruna coin into the hole on the chain. You can take back the coin by locking the bicycle at any stops after use. On the street corner of Odense Denmark and Malmo Swede, where built traffic signs that specially provide service for bicycles, cyclists are very clear about city's actual road condition. Public bicycle services are also provided in Barcelona, Milan, Amsterdam, Washington, Mumbai and other cities.

Public bicycle projects are promoted in 61 cities in China currently. Wuhan is the one of the earlier cities to promote free bicycle system in China. There are about twenty thousand bicycles in operation. Hangzhou is one of the earliest cities to operate public bicycle transportation network system in China. From 63 stops and 2800 bicycles originally, it has developed into 2000 stops and 
500 thousand bicycles by now. It is a rather successful public bicycle system in China, and has become beautiful scenery in Hangzhou.

\section{Case Analysis about Public Bicycle System among Three Cities in Shandong}

With the promotion of green transportation in China, all cities in Shandong plan and carry out the public bicycle system, such as, Qingzhou, Yantai and Zaozhuang.

Basic information of the public bicycle system among the three cities. The basic information of the three public bicycle systems mainly managed by government refers to table 3 .

Table 3 system's basic information

\begin{tabular}{|c|c|c|c|}
\hline Name of the city & Qingzhou & Yantai & Zaozhuang \\
\hline Urban area $\left[\mathrm{km}^{2}\right]$ & 1569 & 2643 & 3078 \\
\hline $\begin{array}{l}\text { Urban population } \\
\text { [ten thousand] }\end{array}$ & 90 & 168 & 234 \\
\hline Operator & $\begin{array}{c}\text { Qingzhou Kaicheng } \\
\text { Public } \\
\text { Transportation } \\
\text { Co.,LTD. }\end{array}$ & $\begin{array}{l}\text { Yantai Public } \\
\text { Bicycle } \\
\text { Management } \\
\text { Co.,LTD. }\end{array}$ & $\begin{array}{l}\text { Changzhou } \\
\text { Yong'an Public } \\
\text { Bicycle System } \\
\text { Co.,LTD. }\end{array}$ \\
\hline Starting time & September 2010 & August 2010 & July 2012 \\
\hline $\begin{array}{l}\text { The number of public } \\
\text { bicycle[bike] }\end{array}$ & 10,000 & 6,000 & 1100 \\
\hline $\begin{array}{c}\text { The number of rental } \\
\text { site[one] }\end{array}$ & 506 & 140 & 41 \\
\hline $\begin{array}{l}\text { Average distance between } \\
\text { rental sites }[\mathrm{m}]\end{array}$ & 300 & 500 & 700 \\
\hline Service time & $24 \mathrm{~h}$ & $6: 30--20: 30$ & $24 \mathrm{~h}$ \\
\hline
\end{tabular}

Operating mode of public bicycle system among the three cities. At present, public bicycle transportation service is promoted in 61 cities in China. Its operation mode can be divided into three kinds.

The mode of QingZhou city: QingZhou government authorized a specialized enterprise for construction and operation management. The government has purchased service from the enterprises for five consecutive years. The relevant departments formulate special supervision appraisal system. The service charged by operating company is linked with the quality of business operation. These measures are welcomed by all parties. There are little government financial subsidies, so it is easy to make budget for annual cost on average. Professional operating company has various experience, perfect management system and stable operation [6]. This mode is also adopted by Kunshan, Changshu and Nantong development zone of Jiangsu and Minhang district of Shanghai [7].

The mode of Yantai city: The public bicycle project of Yantai was promoted from December in 2011. It is compensated in a form that enterprises invest to construction and management, no fund is from the government. The government only provides advertisement space. However, operating enterprise had deficits the government is unable to supervise and exam and the operation quality was poor. The original operating enterprises quit, and are taken over by the Yantai Urban Management Bureau. The above situation is similar to Wuhan city in Hubei and Chizhou city in Anhui.

The mode of Zaozhuang city: Zaozhuang government provided funds to purchase the public bicycle system, assisted suppliers to build infrastructure, and authorized a specialized enterprise to operate and manage. The government ensures enterprises operating expenses through the fiscal subsidy and advertising resources replacement. The government established relevant operation and management departments. Its financial investment is relatively huge, and there are many complaints from citizens at the beginning of the operation. However, the advantage of the service gradually 
comes out and gets widely recognition. Other representative cities are Hangzhou in Zhejiang, Zhongshan in Guangdong, Zhuzhou in Hunan and so on.

Service method of public bicycle system among the three cities. The common features of these three systems are that users make registration and get cards; a small amount of deposit is needed; and the use time within an hour is free but overtime should be paid. And the longer the overtime is, the higher the rate will be. Table 4 calculates the system charges according to the rate of different intervals. If a customer swiped card at a stop, the selected bicycle will be unlocked. The bicycle can be returned at any stop.

\begin{tabular}{|c|c|c|c|c|c|c|}
\hline System name & $1 \mathrm{~h}$ & $2 \mathrm{~h}$ & $5 \mathrm{~h}$ & $10 \mathrm{~h}$ & $24 \mathrm{~h}$ & $>24 h$ \\
\hline Qingzhou system & Free & 1Yuan & 7Yuan & 17Yuan & 45Yuan & $\begin{array}{l}\text { It is calculated in every two } \\
\text { hours for two Yuan. }\end{array}$ \\
\hline Yantai system & Free & 1Yuan & 4Yuan & 9 Yuan & 23 Yuan & 24 Yuan \\
\hline $\begin{array}{l}\text { Zaozhuang } \\
\text { system }\end{array}$ & Free & \multicolumn{5}{|c|}{$\begin{array}{l}\text { There are } 20 \text { scores in credit card; if over an hour, it is deducted a score } \\
\text { for an hour; when the score is zero, it needs to purchase by one Yuan for } \\
\text { one score. }\end{array}$} \\
\hline
\end{tabular}

Pubic bicycle rental site in Qing Zhou can offer three kinds of cards. Visitor card need to pay 300 Yuan deposit and 20 Yuan consumption to recharge. Over 10 visitor cards can exchange a group card, which needs ID of the cardholder and company introduction. Every card needs to pay 100 Yuan deposit and 100 Yuan consumption to recharge. Individuals need to pay 200 Yuan deposit and 100 Yuan consumption to recharge with his or her ID card to exchange their cards. Local residents in Yantai need to pay 100 Yuan deposit and 100 Yuan consumption to recharge with total 200 Yuan to exchange their cards. Tourists must pay 300 Yuan deposit and 100 Yuan consumption to recharge with total 400 Yuan to exchange their cards. Local residents in Zaozhuang need to pay 100 Yuan deposit and 10 Yuan handling fee with his or her own ID card, house property card or registered permanent residence. Others need to pay 200 Yuan deposit and 10 Yuan handling fee with his or her own ID card. All cards in a city adopt the same rate [8].

Implementation effect of public bicycle system among the three cities. Providing convenient, efficient and healthy travel way. Over 44 thousand people exchanged bicycle cards from Qingzhou public bicycle system. More than 6000 people ride public bicycles every day. Average ride times per day reached 14 thousand persons. Yantai had 6000 bicycles, and 13 thousand people exchanged their bicycle cards. They voluntarily participated in the team of "green travel". The average use frequency in a day is about 5000 to 7000 . Zaozhuang adopts the operation mode of "rental sites placed by net borrow and return, service offered in 24 hours". 1100 public bicycles were put into operation, and the number of average use frequency per day is about 1300 to 2000 persons. The traffic congestion among these three cities all had been alleviated.

Energy-saving and pollution reduction. Energy-saving and emission reduction are seen clear by promoting public bicycle system. Table 5 and table 6 have given out the measurement of energy saving and emissions reduction if bicycle replaces bus and personal cars respectively. It shows that the environmental effect is the best if public bicycle replaces person cars.

Table 5 measurement of energy-saving for public bicycle (converted into gasoline No.93)

\begin{tabular}{ccccc}
\hline & $\begin{array}{c}\text { Replacement } \\
\text { percentage }\end{array}$ & $\begin{array}{c}\text { Energy-saving } \\
\text { per person a day } \\
\text { [liter] }\end{array}$ & $\begin{array}{c}\text { Total energy } \\
\text { saving a month } \\
\text { [liter] }\end{array}$ & $\begin{array}{c}\text { Economic value a } \\
\text { month[ten thousand } \\
\text { Yuan] }\end{array}$ \\
\hline $\begin{array}{c}\text { Replacement of } \\
\text { bus }\end{array}$ & $1000: 100000$ & 0.66 & 1200000 & 720 \\
$\begin{array}{c}\text { Replacement of } \\
\text { personal car }\end{array}$ & $2000: 100000$ & 1.66 & 3000000 & 1800 \\
\hline $\begin{array}{c}\text { Note: The data is from Hangzhou Public Bicycle Transportation and Service Development Co., Ltd. } \\
\text { Table 6 the measurement of carbon emission reduction for public bicycle. }\end{array}$ & $\begin{array}{c}\text { Total emission } \\
\text { Replacement } \\
\text { percentage }\end{array}$ & $\begin{array}{c}\text { Emission } \\
\text { reduction per }\end{array}$ & $\begin{array}{c}\text { Economic value a } \\
\text { reduction a month }\end{array}$ \\
\hline \multicolumn{4}{c}{ month[ten thousand } \\
\hline
\end{tabular}




\begin{tabular}{ccccc}
\hline & & person a day[kg] & [tons] & Yuan] \\
\hline $\begin{array}{c}\text { Replacement of } \\
\text { bus }\end{array}$ & $1000: 100000$ & 1.66 & 3000 & 334800 \\
\hline $\begin{array}{c}\text { Replacement of } \\
\text { personal car }\end{array}$ & $2000: 100000$ & 4.17 & 7500 & 837000 \\
\hline Note: The data is from Hangzhou Public Bicycle Transportation and Service Development Co., Ltd.
\end{tabular}

Note: The data is from Hangzhou Public Bicycle Transportation and Service Development Co., Ltd.

Motor vehicle travels one kilometer, while emitting about $160 \mathrm{~g} \mathrm{CO} 2$ volume on average. According to this calculation, from Qingzhou public bicycle annual use times and travel distance for one person, the first year when system implemented, and the $\mathrm{CO} 2$ emissions reduced by 3000 tons. There are 1100 bicycles in Zaozhuang taken into use, which accounts for $10 \%$ of bus travel share and reduces carbon emission by 2000 tons. 6000 public bicycles in Yantai can reduce carbon emissions by 10000 tons.

Improvement of city's image. The implementation of public bicycle system among Qingzhou, Yantai, and Zaozhuang succeeded in improving the city's image. Its welfare services were universally welcomed by residents and visitors. The transportation structure and travel habits have been changed. The unique image of pubic bicycle and rental sites has become beautiful scenery among Qingzhou, Yantai and Zaozhuang, and has improved the urban charm as well.

The national standardization service trial project "the standardization trial site of public bicycle service" declared by Qingzhou city has been approved by National Standardization Management Committee. Qingzhou has become a public bicycle stop and a county of the largest bicycle scale between domestic cities. Its public bicycle now is a name card for Qingzhou. China's Human Rights Development Fund launched a welfare project in Beijing "public bicycle free services system" across the state to boost China's return to green travel, the "bicycle kingdom". 16 trial cities include Yantai. Old Zaozhuang city is a tourist city, advocating travel concepts of "green, low carbon, environment friendly, and leisure" Public bicycle system improved civilization image of tourism cities. Therefore, these cities attract to thousands of visitors.

\section{Experience and Enlightenment from Public Bicycle System among Three Cities in Shandong}

Scientific planning. On the basis of various arguments of scientific planning, reasonable place stops and the number of bicycle, and development space shall be reserved. Stops should be built in the standardized housing areas or around shopping malls, with distance between stops less than 300 meters, about 300 meters in the city main road, and 500 meters in outer city site. Place the bicycle in partial, and adjust the number of bicycle in each stop after trial operation. From operation condition in three cities of Shandong, the number of stop is rare at the beginning of operation the use times per day is relatively low. While, as the system coverage spread, the number of placed bicycle increases, and the use times gradually grows. There are only a few stops in Qingzhou first, and it now has been built 506 stops. The number of bicycle from originally 75 has been developed into 10000; and the bicycle of average use frequency a day is 1.4 times.

Reinforce the management. QingZhou Transport Authorities cooperated with the Qingzhou KaiCheng Bus Company to build Public Bicycle Management Services Company. The company sets six functional departments: monitor operation department, finance department, stops management department, maintenance department, and supervision office etc. Each department carries out the science operation management respectively. First management entirely authorized to enterprise completed in Yantai, but the effect is very poor. Yantai Urban Management Bureau Yangguanchu has begun to intervene in the operations of public bicycle on November 1, 2011, offering repair, maintenance, and test for public bicycle, which enabled the troubled project to gain a new life. Municipal government in Zaozhuang established relevant operations management department; authorized Changzhou Yong'an public bicycle systems Co., LTD, Zaozhuang branch operation management; and the government provided operating enterprises for subsidies according to the reflection of the citizens. Therefore, virtuous cycle was formed. 
Various financing. Now QingZhou mainly makes financial investment, but they also increase business income by selling the rights to stop advertising, operation rights to standing stop etc. Yantai solve its financial problem and enterprise's deficit by mainly selling out 1000 blocks of public bicycle waiting shelter covering five districts for advertisement of light box. Zaozhuang's income is mainly from government subsidies and advertisement. The mode of using public resources revenue rather than simply relying on government funding ensures a relatively stable cash flow, which will contribute to the long-term development of the system.

Reasonable charge. When public bicycle system is fixed to a price among these three cities, welfare and speeding the turnover of public system are also considered. The charge mainly includes three parts: deposit, fees and penalties. Fees will increase with time passing by. It is forfree in the first one hour within the rental period. $90 \%$ of users will return the bicycle within an hour, which embody the meaning of welfare, and shorten the turnover. This is an important guarantee that the system is highly welcomed and successful.

Advanced technology. Public bicycle system needs strong technological support, if it is wanted to be convenient and beneficial for citizens. Three cities depend on the new generation management system of modern and advanced electric technology, information integration, wireless communication and internet technology in China. The existing system technology in China is advanced and practical, which can meet the PBOC2.0 standard of People's Bank of China, and also can support the management system of city pass key for Building Department. The system support China mobile, Unicom, union mobile payment application compatible with citizen's card or bus IC card. Parts of products have been exported to developed countries.

Advocating the concept of green travel. Under the promotion of various governments, supervising departments instruct citizens to concern and support the public bicycle by holding cycling contests, and media broadcasting the concept of green travel. QingZhou held bicycle round travel in September 2011, and held public bicycle cruise "green travel for me first" in April 2012. In order to practice a new life concept "green, low carbon, and environment friendly", Yantai recruited 50 students from a university located in Yaitai to ride bicycle collectively in December 8, 2011, which has become a beautiful scenery. The interview team of "Focus on beautiful Shandong- the ninth China network media in Shandong" experienced public bicycle service system in Zaozhuang. Healthy and cultural activities promote the development of the public bicycles.

\section{Countermeasures to Solve the Problems of Public Bicycle}

Policy and supervision of government. The governments to intensify publicity improve agreement of green travel and to make riding a bicycle become a healthy, fashionable transportation way by using the tool of public opinion. Strengthen the urban road traffic planning; improve the share percentage of public bicycle system; play its leading role to solve the problem in short distance travel and make connection to transfer. Strengthen bicycle separately lanes, construct and reconstruct urban main road and the second road; and set up bicycle lanes. If construction projects are not in accordance with planning and construction of bicycle lanes, urban and rural planning departments shall not issue a planning permission. Combine with urban renewal, environmental renovation, etc. to open closed blocks, to get through dead-end roads, to build more new roads, to perfect bicycle micro circulation system. For those branches have larger traffic volume of motor vehicles and bicycles, reasonably set up facilities, such as barrier for motor vehicles, the car pile, road barrier etc. to prevent motor vehicle driving in bicycle lanes and guarantee its safety. After combining the bicycles' travel features as a chronic traffic, reasonably place the stops, and make it convenient and beneficial for citizens. Provide proper financial subsidies to build systems. Enhance coordination and supervision with the applied enterprise; guarantee continuous and steady operation.

Responsibility and obligation of operating enterprise. Operating enterprises have to take this service as their own business. It is their responsibility and obligation to make it convenient and beneficial for citizens. The enterprises have to establish a scientific management operating system for public bicycle, adopt advanced equipment and advanced technology, and improve technological innovation so to provide better service to citizens. The workers should be strengthen and trained in 
each stop to improve their business quality, and it is essential to cultivate their spirits to dedication. Because public bicycle transportation is an absolute welfare, operating enterprises have to follow the business principle of no profit or sight profit which both makes benefits to citizens and improve the structure of urban transportation. Therefore, the society becomes more harmonious. Operating enterprises have to depend on advanced equipment, scientific management and good service to get recognition.

Participation of citizens. Public bicycle service is a new born service. New things always show the fragility and have many problems, which need to be perfected in the process of operating management continuously. It is very crucial to get understanding and support from citizens. Public bicycle transportation system is a key direction for the diversity of modern urban transportation system. It advocates green travel, and citizens will consider riding bicycles for leisure or other things. Be citizens who obey regulations and laws; follow on-site management of public bicycle system, and use reasonably and take good care of bicycles.

\section{Conclusions}

Public bicycle provide new solution to open urban traffic micro circulation, clear tough urban transportation. Insist the principle of government instruction, market operation and enterprise management, and combined with bus stop, subway station, and transportation hub etc. to place bicycle stops reasonably, and make it systemization, internalization and humanization. Focally enhance the infrastructure construction of urban bicycle transportation system; improve travel conditions for bicycles and encourage residents travel by bicycles; so to improve overall level of urban public travel. Although there are many problems in public bicycle rental service system, its developing tendency has become irresistible. Value the construction and stops placement for bicycle lanes, integrate the system of public bicycle transportation transfer, perfect management system for bicycle, and improve citizens' awareness of low carbon travel, so to create conditions for better development of public bicycle system. With the advancement of scientific technology, the future public bicycle system must be more intellectual, humanistic, environment-friendly and healthy. The development of public bicycle definitely will have a bright future.

\section{References}

[1]The Building Department, the National Development and Reform Commission, Ministry of Finance issued guidance on strengthening the construction of urban pedestrian and bicycle system(construction [2012] No. 133).September 5, 2012.

[2]J. Pablo, J. B. Rouquier, O. Nicolas, and R. CÉLine. 2010. Characterizing the speed and paths of shared bicycles in Lyon, Transportation Research: Part D, 8(15):522-524.

[3]J.R.Lin, and T.H.Yang. 2011. Strategic design of public bicycle sharing systems with service level constraints, Transportation Research: Part E, 47(2):284-289.

[4]Bin Huang. 2010. An evaluation of Hangzhou public bicycle system, Urban Planning Forum, (6):72-79.

[5]Wang Zhigao. Cases and enlightenment from the third generation of public bicycle systems in Europe. Urban transportation. July (April) 7-12, 2009.

[6]Du Jun, LiuGuanglai, LiuGuolei. Qingzhou mode:open up public traffic microcirculation. People bus. August 2012.

[7]Chen Xiaomin, Li Bing. Exploration and research city public bcycle system - take an example of public bicycle in Minhang district, the market weekly (theory and exploration), January 2012. 120121.

[8]Information on:http://www.publicbike.net. 